\title{
The Development of the Philippine General Hospital as a Referral Center in the COVID-19 Pandemic: A Qualitative Study
}

\author{
Jean Anne B. Toral, MD, MSc, ${ }^{1,2}$ Michelle V. Alba, MMBM, ${ }^{1}$ Zaldy R. Reyes, $\mathrm{RN}^{1}$ and Al Joseph R. Molina, MD \\ ${ }^{1}$ Expanded Hospital Research Office, University of the Philippines - Philippine General Hospital \\ ${ }^{2}$ Department of Obstetrics and Gynecology, College of Medicine and Philippine General Hospital, University of the Philippines Manila
}

\begin{abstract}
Background. The University of the Philippines-Philippine General Hospital (UP-PGH) was designated as a COVID Referral Center for one cluster in Metro Manila during the pandemic. We reviewed and described how UP-PGH prepared for this endeavor. This can serve as reference for similar events in the future.

Methods. We conducted a qualitative cross-sectional study with 20 key informant interviews and 5 focus group discussions involving 32 hospital front liners. All proceedings were transcribed and analyzed manually following the conceptual framework. Minutes of meetings, memoranda, and other official materials and communications were also reviewed.
\end{abstract}

Results. The salient points of both internal (operations, structure, staff, supplies, and continuation of regular services) and external aspects (relation with other hospitals, the local government, the national health authority, and the general public) were enumerated and elaborated. Both best practices and areas needing improvement were identified.

Conclusion and Recommendations. The UP-PGH tried its best to prepare and respond to the COVID-19 pandemic by protecting its hospital personnel and delivering evidence-based and quality care to patients. The response was not a perfect one and there were certain aspects for improvement.

Key Words: COVID referral center, pandemic, qualitative study

\section{INTRODUCTION}

Corresponding author: Jean Anne B. Toral, MD, MSc Expanded Hospital Research Office

University of the Philippines - Philippine General Hospital

Department of Obstetrics and Gynecology

Philippine General Hospital

University of the Philippines Manila

Taft Avenue, Ermita, Manila 1000, Philippines

Email: jbtoral@up.edu.ph
On March 11, 2020, the World Health Organization (WHO) declared COVID-19 from the Severe Acute Respiratory Syndrome coronavirus 2 (SARS-CoV-2) a pandemic due to the large number of cases in over 110 countries. This declaration triggered governments to activate preparedness plans and take emergency procedures with the aim of protecting the public. In the Philippines, Code Red Sublevel 2 (sustained community transmission beyond capacity) was raised on March 12 followed by enhanced community quarantine. Subsequently, UP-PGH, the national university hospital was requested by the Department of Health $(\mathrm{DOH})$ to be the designated COVID-19 referral hospital for one cluster in Metro Manila. On March 23, the PGH Director announced acceptance of this designation, but requested for time to prepare the hospital. On March 30, the PGH officially became a functioning COVID referral center with an initial 130-bed allocation of its 1,500-bed capacity. 
Prior to the spread of the Severe Acute Respiratory Syndrome coronavirus 2 (SARS-CoV-2) that started towards the end of 2019, the more recent infectious outbreaks were also caused by coronaviruses, namely: SARS in $2003^{1}$ and the Middle East respiratory syndrome (MERS-CoV) in 2014. ${ }^{2}$ The SARS outbreak in 2003 was contained but not before more than 2 dozen countries were affected with a little over 8,000 cases and 774 deaths. The MERS-CoV outbreak involved just more than 8,000 cases and 774 deaths. These events emphasized the need for greater preparedness and coordination to come up with countermeasures and a better public health campaign.

The preparations of healthcare institutions during the SARS outbreak in 2003 proved to be excellent learning points for the current pandemic. Taiwan, in particular, a victim of the SARS 2003 outbreak, came up with a comprehensive public health program 10 years after. Taiwan was successful in improving collection of disease surveillance data, running a state-of-the art Epidemic Intelligence Center for integration, analysis, and reporting surveillance data, creating a functional network of laboratories for performance of rapid diagnostic tests, and establishing a medical network to provide expert advice and recommendations to their DOH and Center for Disease Control (CDC) on medical response and disease control. ${ }^{3}$ Taiwan was one of the few countries with the best response to this current COVID-19 pandemic.

In 2014, the WHO came up with its guidelines on "Hospital Preparedness for Epidemics." ${ }^{4}$ Its adaptation should take into account local risks, requirements, norms, and practice. The WHO recognized the critical role of hospitals and healthcare facilities in communicable disease epidemics and emergencies. The aim was that hospital management has established mechanisms for developing and implementing a Hospital Emergency Risk Management Program. At present, the Centers of Disease Control (CDC) has come up with a comprehensive hospital preparedness checklist for COVID-19 for use in US hospitals. ${ }^{5}$
The framework for the preparation followed internal and external aspects (Figure 1). This included the internal systems to fulfill the overall plan that the hospital needed to prepare for the task at hand. At the same time, continuation of the operation of the essential services of the hospital could not be neglected. There were also several external systems that the hospital needed to coordinate with, foremost of which was the national health authority (the $\mathrm{DOH}$, in our case), the local government units, and other hospitals. The biggest external system was the public for which this endeavor was being undertaken.

In this study, we reviewed the preparations taken by UP-PGH, the national university hospital, to take on this task to manage this outbreak. These included operations, structure, staff, supplies, continuation of regular services, as well as coordination with other hospitals, the national health authority, the local government, and the public, from the point of view of the administrators and the front liners. We identified best practices as well as areas that needed improvement.

\section{METHODS}

We conducted a cross-sectional study using qualitative methods involving key informant interviews (KII) and focus group discussions (FGD). For the KIIs, we identified 20 key informants who were the most knowledgeable on the processes, namely members of the Executive Committee, COVID Crisis Management Committee and other personnel essential to the preparations.

1. PGH Director

2. Crisis Management Committee heads (3) - operations, logistics, and manpower

3. Information and Education Committee (IEC) head

4. COVID Training Committee head

5. Hospital Infection Control Unit (HICU) head

6. Critical Care Unit-Management Action Team (CCUMAT)

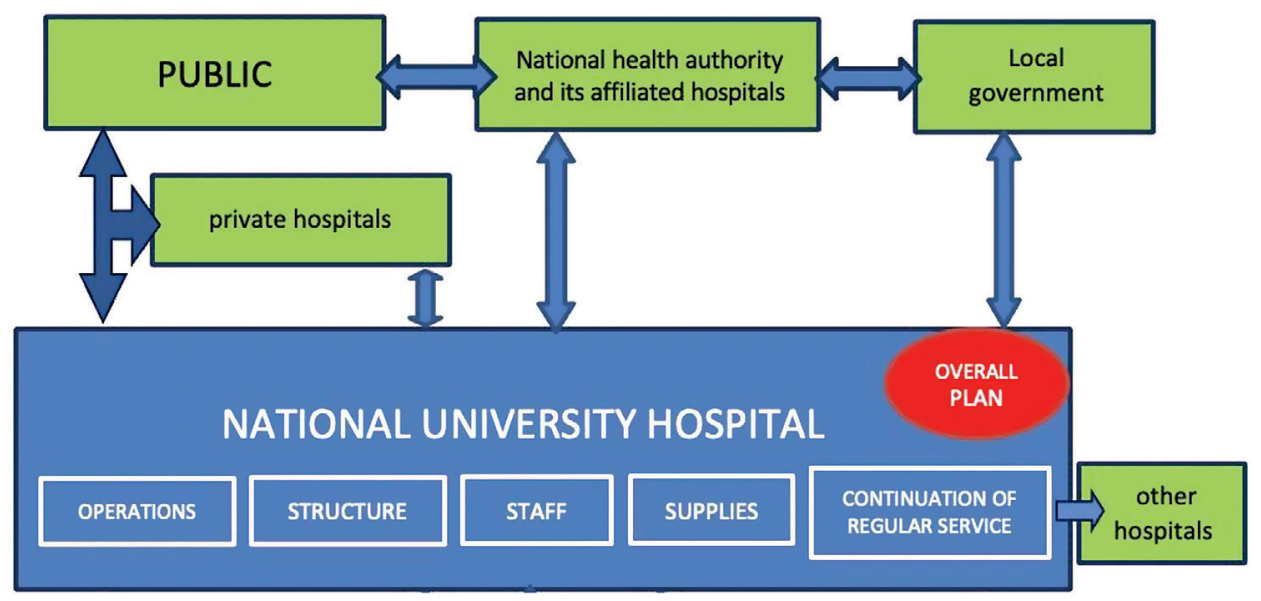

Figure 1. Framework for the making of a hospital as a referral center for a pandemic. 
7. Operating Room Management Team (ORMAT) head

8. Head of Health Service

9. Head of Laboratories

10. Head of Property and Supply

11. Head of Therapeutics Committee

12. Head of Engineering

13. Consultant architect in charge of infrastructure

14. Deputy Directors for Health Operations, Administration, Fiscal Services, and Nursing (4)

15. Coordinator for Service

Focus group discussions were conducted with medical front liners, namely doctors, nurses, paramedical personnel (phlebotomists and radiology technicians) and institutional workers. Medical front liners were defined as having worked in the "hot zone" of the hospital, that is, in the COVID wards or had direct contact with COVID-positive patients for procedures. Five FGDs were conducted with a total number of 32 participants. The KI and the FGDS were conducted using a semi-structured format with a general interview guide composed of the following open-ended questions:

\section{For the KIls:}

1. What do you think about PGH pre-COVID?

2. When you heard about the news making PGH one of the COVID referral centers, what were your thoughts? What do you think was PGH's level of preparedness to accept this task?

3. What steps did you or your committee make to prepare PGH as a COVID referral center? What problems did you encounter? How did you overcome those problems?

4. During the actual operations, were there adjustments you had to make?

5. What lessons did you learn in the preparation and in the execution of the COVID-19 plan (both best practices and miscalculated moves)?

6. How do you think this planning and this experience as a whole will help PGH in the future?

\section{For FGDs:}

1. What do you think about PGH pre-COVID?

2. When you heard about the news making PGH one of the COVID referral centers, what were your thoughts?

3. Was the plan of the hospital committee handling the COVID crisis clear to you? If not, how did you clarify?

4. Do you think the preparations were sufficient for the task given to PGH? Why? Why not?

5. What would you recommend to further improve the response of $\mathrm{PGH}$ to health threats like this?

6. How do you think this experience as a whole will help $\mathrm{PGH}$ in the future?

As necessary, elaboration and clarificatory probe questions were asked. All proceedings of the KIIs and FGDs were recorded and transcribed verbatim. Manual analysis of data was made with sorting of the answers into groups based on the conceptual framework. Minutes of meetings, memoranda, and all official materials and communications related to the subject matter were also collected and reviewed.

Table 1. Demographic characteristics of the FGD participants

\begin{tabular}{|c|c|c|c|}
\hline Characteristic & $\begin{array}{l}\text { Residents and } \\
\text { Fellows }(n=13)\end{array}$ & $\begin{array}{l}\text { Nurses } \\
(\mathrm{n}=14)\end{array}$ & $\begin{array}{l}\text { Paramedical } \\
\text { Personnel and } \\
\text { Institutional } \\
\text { Workers }(n=5)\end{array}$ \\
\hline $\begin{array}{l}\text { Gender } \\
\text { Male } \\
\text { Female }\end{array}$ & $\begin{array}{c}3 \\
10\end{array}$ & $\begin{array}{c}3 \\
11\end{array}$ & $\begin{array}{l}2 \\
3\end{array}$ \\
\hline $\begin{array}{l}\text { Age (in years), } \\
\text { Mean (Range) }\end{array}$ & 29.2 & $\begin{array}{c}37.5 \\
(28-52) \\
\end{array}$ & $\begin{array}{c}34.2 \\
(25-55) \\
\end{array}$ \\
\hline $\begin{array}{l}\text { Length of } \\
\text { service } \\
\text { (in years), } \\
\text { Mean (Range) }\end{array}$ & $\begin{array}{c}\text { YLI - } 6 \\
\text { YL II - } 2 \\
\text { YL III - } 3 \\
\text { YL IV - } 2 \\
\text { YL II fellowship - 2 } \\
{ }^{*} \text { Recorded as their } \\
\text { year level in residency } \\
\text { or fellowship }\end{array}$ & $\begin{array}{l}12.7 \\
(4-30)\end{array}$ & $\begin{array}{c}10.2 \\
(1-27)\end{array}$ \\
\hline
\end{tabular}

YL, Year level

\section{RESULTS AND DISCUSSION}

We interviewed 20 key informants who were currently employed as medical specialists or regular staff of the hospital who are in their current position ranging from 10 months to 16 years. The heads of the Crisis Management, Information and Education, and COVID Training Committees were newly designated in response to the COVID pandemic.

Five FGDs were conducted: two with residents and fellows, two with nurses, and one with paramedicals and institutional workers (Table 1).

Following the proposed conceptual framework, we enumerated the internal aspects of preparations for UPPGH to become a COVID referral center: operations, structure, staff, supplies, and continuation of regular services based on responses gathered (Table 2). Details of responses from KIIs and FGDs are in Appendix Tables 1 to 5. These internal aspects of the preparation were also linked with items external to the hospital including other coordination with other hospitals, the national health authority, the local government, and the general public.

\section{Operations}

1. Setting of terms with the national health authority (Philippine DOH)

To put order in the operations, only COVID-positive patients would be taken in through coordinated transfers. The hospital was ensured the full support of the $\mathrm{DOH}$ with regard manpower, augmentation, and funding. A command center was established for the coordination of transfers. 
Table 2. Internal aspects of the PGH preparation as COVID-19 Referral Center

\section{Aspect} Operation
1. Setting of terms with $\mathrm{DOH}$

2. Establishment of the Command Center

3. Organization of the Crisis Management Committee

4. Central role of the HICU - policies, standard operating procedures, protocols, medical management, infection control and prevention, surveillance

5. Planning of surge capacity (related to other hospitals and local government)

6. Visitor access

7. Computerization (paperless, electronic)

8. Digitalization of radiographic images

9. Designation of a safety officer

10. Dialysis Unit within the COVID area

11. Zoning of the areas

12. Central swabbing area

13. External communication through the designated spokesperson

\begin{tabular}{ll}
\hline Structure & 1. Building preparation \\
& 2. Engineering maintenance \\
& 3. Operating Room readiness \\
& 4. Laboratory facility for testing \\
& 5. Internal communication \\
6. Postmortem care \\
\hline Staff & 1. Building the manpower complement (with aid \\
& 2. Trom DOH) \\
& 3. Physical care and protection \\
& 4. Telemonitoring by the Health Service \\
& 5. Psychological support \\
& 6. Support for transportation and housing \\
\hline Supplies & 1. Building the "war chest" \\
& 2. Stockpiling of consumables \\
& 3. Acquisition of durable medical equipment \\
& 4. Drug stockpiling \\
\hline Continuation of & 1. Storage \\
regular services & 2. Tetworking with other non-COVID hospitals \\
& 3. Online consultation and appointment system \\
& 4. Planning of gradual return of regular hospital \\
\hline
\end{tabular}

\section{Crisis Management Committee}

The creation of this committee was based on the principle "leave the science to the internists and let the surgeons handle the logistics." The science was based on well-appraised evidence and an organized clinical approach. All policies related to the response to the pandemic was centralized, emanating only from the Hospital Infectious Control Committee (HICU). The science group was tasked to inform the logistics group on their needs, and the logistics group had to provide these needs. There was a designated overall operations head. Two other heads comprised the Crisis Management Committee triumvirate, the person incharge of manpower (referring to all resources that move, i.e., the staff), and the person in-charge of the logistics (referring to all resources that do not move, i.e., the supplies). Amidst all these preparations, the most important objective of the Crisis Management Committee as verbalized by its overall chief of operations was "Protect the healthcare worker." It was of utmost importance that the staff were comfortable because they knew they were protected.

\section{Central role of HICU}

HICU handled the science - the protocols, policies, standard operating procedures, medical management, infection control and prevention, and surveillance - based on evidence-based guidelines, mainly from the CDC, the WHO, and our local society, Philippine Society for Microbiology and Infectious Diseases, Inc. (PSMID). According to the HICU chief, "No institution can ever really be prepared enough but we are trying our best." HICU also dealt with coping with the fear of the healthcare workers. Many feared the unknown and the invisible opponent coupled with doubts of readiness of the hospital. HICU addressed this seriously knowing fully well that "the mindset of the staff is most important" as stated by its chief. This was in agreement with the priorities of the director and the overall chief of operations.

\section{Planning for the hospital's surge capacity}

This planning was three-pronged. The overall chief of operations likened the PGH capacity to a rubber band. First, there were strategies to help increase the hospital bed capacity for COVID, which was initially set at 130 but grew to 220. The "normal" operations of the hospital had to stop for the time being. Protocols for closure of regular services were made, including that of the outpatient services and elective surgery services. Identification of and coordination with alternate facilities in the area where these "normal" services could be provided were made. Constant communication with the local government helped in this aspect. At the start, this system was not yet well-established, leading to confusion on networking for non-COVID patient transfers. Second, there were strategies to maximize the number of staff available for direct patient care (to be elaborated under Staff). Third, the hospital contributed to capacity-building of other institutions so that they could take care of the milder cases of the disease. PGH helped in setting up quarantine facilities in the city and hooked them up with the PGH testing center. The same was done for another health service of the University System. PGH also supported the local government's COVID hospital with manpower, supplies and testing. In these ways, PGH narrowed their COVID clients to the moderate and severe types.

\section{Visitor access}

As the COVID patients could not be visited due to its infectious nature, the "Tele-Kumusta” technology was created. Hosted by the hospital's medical social service, families were able to "see and visit" their loved ones through television connectivity. The tele-presence technology also served as a way for the doctors to do patient rounds. 


\section{Electronic and paperless technology}

Medical records and transactions became electronic and paperless as well. The existing Registry of Admissions and Discharges (RADISH) assumed a bigger role to include not just orders but all sections of the chart - vital signs, laboratories and other diagnostic results. The Computerized Audited Records Retrieval and Online Tracking (CARROT) served as the transition from extensive paper-based charts to the electronic one. A dashboard at the Command Center mapped out all COVID admissions and provided information on available and unavailable beds in just one glance. It was also accessible through the institution's connectivity system via any smart phone or device. Endorsements were also held through the dashboard.

\section{Digitalization of radiographic images}

Already in place prior to the pandemic, its completion of the digitalization process served the front liners well by greatly conserving energy and time.

\section{Designation of a Safety Officer per duty}

As many front liners commented, "When somebody watches you don and doff the personal protective equipment (PPE) right, it gives you confidence."

\section{Dialysis unit within the COVID areas}

As several patients with COVID developed kidney complications requiring hemodialysis, the establishment of a dialysis unit within the COVID areas (called SCOVIDDO) proved an excellent strategy to minimize patient movements and delimiting the restricted areas.

\section{Zoning of hospital areas}

Delineation of areas with presumed air contamination guided the hospital staff into appropriate levels of protection to be observed in each of the areas.

\section{Creation of a central swabbing area}

Safe and efficient testing was required as a fundamental feature of the fight against this disease to minimize exposure and save on manpower.

\section{Designation of a spokesperson for external communication}

It was very essential to impart information on what was happening in the hospital to the general public. The general public wanted to know how the situation was in a major COVID referral center.

\section{Structures}

\section{Building preparation}

The WHO guidelines necessitated the creation of negative-pressure rooms, or in its absence, unidirectional flow of air exchange. ${ }^{4}$ An architect was engaged to work together with the hospital and institution engineers and the private sector. Given that PGH is an old structure, the architect ensured the redesigning of air movement (enhanced airflow with 6 exchanges per hour) and proper ventilation to provide protection to the hospital personnel. The architect emphasized that "In the future, hospital buildings must have a masterplan that is easily adaptable, that is, easy to convert to the needs of the situation." This meant that if and when a new structure is built, the negative pressure set-up should be incorporated into the building.

\section{Engineering maintenance}

The head engineer of the hospital considered coordination of technical and medical aspects before execution of any of the projects as best practice. All engineering designs were HICU-approved. Due to numerous items needing repair and maintenance, prioritization of urgent concerns and assigning key personnel-in-charge were very important to minimize wasting of resources. An important engineering concern, hazardous waste disposal, had to be in concurrence with environmental compliance certification. The hospital had the proper equipment and system for this even before the pandemic.

\section{Operating room readiness}

The postponement of elective surgeries was one way of addressing surge capacity. Surgeries were limited to "emergencies" which were carefully defined. As in the rest of the hospital, the delineation of COVID spaces in the operating room complex was made. Supplies and preventive maintenance of equipment had to be checked. The system process flow in the operating room and guidelines had to be laid down and simulated. Manpower complement was reviewed. The chief of the operating room realized that "the physical set up is not perfect but designing a system process flow should be able to protect the healthcare worker."

\section{Laboratory facilities for testing}

The setting up of a COVID testing facility was very critical in the response to this pandemic. It was not only the hospital but the entire university that worked on this. Facilitating the release of the test results was the next critical thing to shorten the "indeterminate" status of any patient. The head of the laboratories attributed the best practices for the laboratory's response to: PGH's capability to train personnel fast coupled with quick mobilization adaptability of the staff (including physician trainees who learned new laboratory methodologies); care for one another and safety in the workplace; facilitated procurement of necessary machines together with preventive maintenance; retention of networks with other laboratories; and modules from the specialty society of pathologists to serve as guide for laboratories handling COVID tests. 


\section{Communication facility}

The Information and Education Committee (IEC) was responsible for internal communication. The head of the IEC knew that crisis communication was very important. The two big goals of the committee were to prevent the crisis of confusion and to keep PGH healthy. The challenge was, in the words of the IEC Committee head, "How can I help HICU delivery their message?" The strategy was to cover all bases and ensure shared responsibility among the administrators and hospital personnel. Everyone looked after their own ranks ensuring that all communications were trickled down to the staff through whatever means. Infographics were the methods used and prepared by very talented personnel. The making of infographics meant sifting through the information thoroughly to come up with an accurate, correct and understandable message. All infographics came out in English and Tagalog versions. Timely release of infographics required anticipation and forward thinking as events developed and unfolded fast.

\section{Postmortem care}

This involved identification of pathways for corpse transfers. This also needed a dedicated corpse carrier, a closed vehicle and a 24/7 driver wearing PPEs. As the Coordinator for Service put it, "even the dead need to be taken care of." Postmortem care also meant there should be no overflow of cadavers in the facility and that these bodies be given dignity. The medical social service worked extra hard to ensure this. Connections with the local government, regional development authority, and some private funeral services were maximized for this.

\section{Staff}

Staff was defined as the manpower resources of the hospital ("all that move").

\section{Manpower complement}

The objectives of manpower support were: 1) complete duty coverage in the COVID-designated areas; 2) health worker safety in the workplace; 3) post-duty housing that was comfortable, safe, conducive for fast recovery; 4) recruitment of additional health workers to ensure adequate staffing of the workplace; and 5) proper and standardized training of all health workers that is compliant with infection control guidelines.

The head of the Manpower Committee's guiding principle was "form before function." Staffing estimates from physicians all the way to the cleaners were made to ensure the optimal number needed per area for minimal contact exposure. The staff was divided into three teams, a design used by hospitals in Wuhan, China where the SARS-CoV-2 originated, with one week of duty followed by two weeks off duty, serving as quarantine period.
Another principle for manpower complement was "all hands on deck." This meant building up manpower by pulling out staff from all other departments. The Medicine Department designed the day-to-day operations while the Manpower Committee supplied the people. Personnel were designated as Intensive Care Unit (ICU)-capable and ward-capable leading to appropriate area assignments. This resulted in a dynamic set-up where COVID management pathways were in place, but the internists were on call. Manpower augmentation from the national health authority, $\mathrm{DOH}$, was also a big help.

\section{Training and education}

Having the manpower was not enough. There was a need to train and educate them. The staff had their respective trainings including that of basic response to an infectious outbreak, crisis situations, and proper donning and doffing of personal protective equipment (PPEs) through simulations and videos. Training came in the form of videoteleconferencing, orientation sessions, regular huddles, and drills of pathways. Training and education also ensured that no one would be left behind untrained and uneducated. It also meant drafting of primers by certain teams (e.g., Anesthesiology, Surgery, Obstetrics) that contained their protocols for specific tasks. The anesthesiologists, for example, had simulation of COVID intubation using video laryngoscopes and aerosol boxes. They also had a dedicated Airway Team for COVID headed by the most experienced anesthesiologist-on-duty. There was a ready intubation box with complete intubation needs (based on a checklist). The best route for intubation calls was also determined.

\section{Physical care and protection for the staff}

Constant availability of appropriate PPEs was part of essential care of the health care workers. A policy of HICU to fit-test all masks and respirators for each employee was a best practice learned all the way back to SARS in $2003 .{ }^{6}$

\section{Health Service's telemonitoring system}

The hospital Health Service monitored all personnel in the hospital including contractual and outsourced employees. This included periodic surveillance with COVID testing for all employees, the very first of which was done three months after the declaration of the hospital as a COVID referral center. A $2 \%$ infection rate among the close to 5,000 employees was comparable to reports of other centers caring for COVID-19 patients. ${ }^{7}$

\section{Psychological support}

Psychosocial interventions from the HICU and, as necessary, from psychiatrists were provided by the hospital. Support groups within the hospital ensured updating, catch-up sessions and debriefing. 


\section{Support for transportation and housing of staff}

The hospital planned to accommodate approximately 1,800 personnel at any one time. The enhanced community quarantine $(\mathrm{ECQ})$ in place meant that there was no public transportation. The hospital administration provided transportation for the personnel to be able to report for work. The private sector, through various foundations, played a big role in providing the healthcare workers free transportation with guaranteed seats in sanitized vehicles. Innovative electric kick scooters were also lent for free. Accommodations in nearby dormitories and hotels were also arranged.

\section{Addressing the hazards of work}

Addressing the hazards of work included admission and care at the hospital when a healthcare worker got the infection. Extra pay for working in the COVID areas had to be as equitable as possible. The mechanism to make the distribution rational was left to the highest official of the hospital. Two things that the health care workers would appreciate though are simple gestures of recognition and the establishment of a feedback mechanism from the ground where the action was.

\section{Supplies}

Supplies referred to the logistical needs ("all that do not move"). The best thing that happened to PGH being a COVID referral center as far as supplies were concerned was that it became a "magnet for donors" as the head of the Logistics Committee termed it. The hospital was supported by the government, private organizations and individual donors. Republic Act No. 11469 known as the "Bayaniban Act to Heal as One Act" gave more leverage to the hospital. ${ }^{8}$

There was urgency in the situation. There was also a non-existent supply chain because of the ECQ. Getting the supplies was through negotiated procurement through the "Bayaniban Act" and personal contacts.

\section{Building the "war chest" of the hospital}

To ensure that the war chest was big and deep, reprogramming the savings of the hospital and cutting off some regular services of the hospital were done. The commitment of the government to direct agencies to cut their maintenance and other operating expenses (MOOE) by $10 \%$ to give to COVID referral centers also helped. The commitment of the University System to support this cause gave a big lift also. Aside from this commitment, the "Bayaniban Na" COVID Operations was the UP President's directive ably supported by the UP Manila Chancellor to be the organized call center for COVID and the centralized recipient for donations. Lastly, the donations of private organizations and individuals came at the most appropriate time. As the head of the Fiscal Services Office said, "donations came at a critical time - at a time when you needed to buy something and there was still something to buy."

\section{Stockpiling of consumable supplies}

The PPEs were the initial problem. A physicianconsultant was designated to be in charge of allocating the appropriate PPEs for the health personnel, including designing contingency plans for shortage, such as disinfection and reuse of these PPEs. ${ }^{9}$ Safety officers also helped to keep track of the daily PPE needs of the health care workers.

\section{Acquisition of durable medical equipment}

The Chief of the ICU oversaw the procurement and upgrading of respirators and high-flow cannulas during the previous hospital administration. Supplies also came with manpower, as respiratory therapists were part of the ICU complement staffing even prior to the pandemic. New acquisitions of these durable medical equipment meant careful scrutiny of quality by a designated group before any procurement. The ingenuity of the Filipino with do-it-yourself (DIY) ventilators also kept the number of respirators in the hospital sufficient. The team approach at the ICU complemented the supply of these durable medical equipment.

\section{Drug stockpiling}

Drugs essential for COVID care had to be procured quickly and were regarded as "emergency" drugs. The regular bidding process was removed for these items. A "compassionate use" in the time of the pandemic justified all these purchases. The pharmacy kept a "COVID Board" to monitor the stockpile of drugs. The head of the Therapeutics Committee recommended looking for automated fasttrack systems for the easier monitoring of the supplies of essential medications should a similar situation occur again.

\section{Storage}

The stockpiling of supplies required a more focused inventory system and a more systematic way of distributing supplies with accountability by the end-user, as recommended by the head of the Office of Administration. Supplies were also related to the staff or manpower. Centralization of human resources as well as good succession plan in any unit handling supplies ensure better accountability.

\section{Continuation of regular services}

\section{Networking with other non-COVID hospitals}

Having been designated a COVID referral center meant that PGH had to stop many of its regular services to concentrate staff, structure, and supplies to the management of COVID. It was difficult to maintain a "normal" hospital at the start. PGH was in the "abnormal" mode right away. Networking with other non-COVID hospitals within the locality and other areas was very crucial. As the months passed and with increasing mastery of the COVID response and better education of the general public on preventive measures, there was a need to gradually re-open the regular 
services of the hospital to lessen the negative impact of closure of services on patients suffering from non-COVID conditions. They are the still unquantifiable collateral damage of the pandemic up to the present.

\section{Telemedicine}

Telemedicine became a formal system in the hospital as many specialties designed their respective mechanics.

\section{Online consultation and appointment system}

The establishment of the online consultation and appointment (OCRA) system proved to be helpful to many patients with means for connectivity.

\section{Planning of gradual return of regular hospital services}

The return of regular hospital services had to be planned meticulously by medical and surgical teams. The return also coincided with the decreasing number of COVID cases. Realignment of staff, supplies, and structures and reorientation of the operations were made. This return did not mean a complete return to normal but a gradual and calculated one considering the ongoing basic response to an infectious outbreak. This included washing hands, wearing PPEs, and social distancing, plus regular surveillance of health care workers. All patients who went to the hospital had to undergo thorough screening. As the hospital gradually returns to the regular services. it is bound to benefit from the technology that was hastened because of the pandemic response.

All these items addressed by the hospital are in line with comprehensive checklists on hospital management preparedness tools like those developed by the CDC for COVID $-19^{5}$ or by other groups like that of Aminizadeh et al. $^{10}$ The true test of hospital preparedness by any institution as a response to such a biologic event, though, may best be measured not by any checklist but by how much it has protected its personnel and by the delivery of care of the patients in the hospital.

\section{CONCLUSION AND RECOMMENDATIONS}

The University of the Philippines-Philippine General Hospital did its best to prepare and execute its plan as a COVID referral center in a short time despite physical limitations. The approach centered on four internal aspects anchored on a well-defined operational plan, from which followed the structure, complemented by the staff (manpower) and supplies (logistics). This operational plan, however, was evolving and flexible to conform to new developments of the disease. The continuation of regular services remains a work in progress. In one way or another, all preparations and executions had to be coordinated with the external stakeholders, namely other hospitals, local government, national health authority, and the general public in a mutually beneficial manner.

The hospital preparedness response was a not a perfect one as there were certain aspects that could have been improved. However, it brought forth many best practices such as: a refresher for the hospital on the basic response to an infectious outbreak, fast-tracking of technological innovations, resilience and adaptability of staff and systems, and the "bayaniban" [camaraderie] spirit of the community. As the hospital moves forward, improvements in handling resources and people where respect and care for one another are of high value will always be regarded as positive attributes. As part of the preparation for future occurrences of biological events such as this infectious outbreak, we recommend that the hospital ensures that new structures to be built are adaptable to disease situations, espouse further advances in technology in hospital systems, and maintain its networks and collaborations.

\section{Statement of Authorship}

All authors participated in the data collection and analysis and approved the final version submitted.

\section{Author Disclosure}

This endeavor was initiated by the Research Office of the hospital independent of the Crisis Management Committee which handled the COVID pandemic response.

\section{Funding Source}

Expenses incurred in the conduct of this research was taken from the regular budget of the research office of the hospital.

\section{REFERENCES}

1. Centers for Disease Control and Prevention. Severe Acute Respiratory Syndrome (SARS): Basic Fact Sheet [Internet]. 6 December 2017 [cited 15 February 2021]. Available from: https://www.cdc.gov/ sars/about/fs-sars.html.

2. Modjarrad K. Treatment strategies of Middle East respiratory syndrome coronavirus. J Virus Erad. 2016; 2:1-4.

3. Center for Biosecurity of UPMC for Taiwan Department of Health. Taiwan's public health emergency preparedness program 10 years after SARS [Internet]. December 2012 [cited 15 February 2021]. Available from: https://www.centerforhealthsecurity.org/our-work/ pubs_archive/pubs-pdfs/2012/2012-12-21-taiwan_assessment_ rpt.pdf

4. World Health Organization (WHO). Hospital Preparedness for Epidemics [Internet]. 4 April 2014] [cited 15 February 2021]. Available from: https://www.who.int/publications/i/item/hospitalpreparedness-for-epidemics

5. U.S. Department of Health and Human Services, Centers for Disease Control and Prevention. Comprehensive Hospital Preparedness Checklist [Internet]. 25 March 2020 [cited 15 February 2021]. Available from: https://www.cdc.gov/coronavirus/2019-ncov/hcp/ hcp-hospital-checklist.html

6. Loutfy MR, Wallington T, Rutledge T, Maderski B, Rose K, Kwolek S, et al. Hospital preparedness and SARS. Emerg Infect Dis. 2004 May; 10(5):771-6. 
7. Berba R, Berberabe E, Veloso J, Dofitas R, Genuino L, Legaspi G. PGH shares lessons learned in war against COVID-19. Excerpts from best practices gleaned from the hospital's experience as COVID-19 Referral Center [Internet]. 15 August 2020 [cited 15 February 2021]. Available from: https://lifestyle.inquirer.net/ 368556/pgh-shares-lessons-learned-in-war-against-covid-19/.

8. Implementing Rules and Regulations of Sections 4 (aa) of Republic Act No. 11469, Otherwise Known as the "Bayanihan to Heal as One Act" [Internet]. 1 April 2020 [cited 15 February 2021]. Avaiable from: https://www.officialgazettte.gov.ph/downloads/2020/ 03mar/20200401-IRR-RA-11469-RRD.pdf.
9. Baticulon RE. Why do Filipino health workers keep getting infected with COVID-19? CNN Philippines Life [Internet]. 13 May 2020 [cited 15 February 2021]. Available from: https://cnnphilippines. com/life/culture/2020/5/14/health-workers-opinion.html

10. Aminizadeh M, Farrokhi M, Ebadi A, Masoumi GR, Kolivand P, Khankeh HR, et al. Hospital management preparedness tools in biological events: A scoping review. J Educ Health Promot. 29 Nov 2019; 8:234.

\section{APPENDICES}

Appendix Table 1. Responses on the questions on thoughts of PGH pre-COVID

\section{Theme of answers}

Sufficiency

\section{With regard what} the hospital does

With regard the people
KIIs

"We are secure. We practically have all the specialties."

"Probably we have the most complete specialists and the magnitude of our service is big." "We have funds from government at the start of the year"

\section{KIls}

"We are comfortable, we are ok."

\section{FGDs}

"Am so proud that I am part of PGH."

"Overall, masaya ako sa PGH." [I am happy in PGH.]

"Okay na rin naman yung compensation ng PGH kaya patuloy pa rin kaming nagseserve." [The compensation in PGH is alright so we continue to serve.]

\section{FGDs}

"Very busy" "Overwhelming"

"Lots of patients, lots of learnings"

\section{FGDs}

"People are accommodating inspite of all difficulties"

"Not so much conscious into the practice of hygiene"

Appendix Table 2. Responses on thoughts when PGH was designated a COVID referral center

\begin{tabular}{ll} 
Thoughts & \multicolumn{1}{c}{ Responses } \\
Fear & $\begin{array}{l}\text { FGDs } \\
\text { "Una po, takot, naalala ko mga anak ko." (First is fear, I remembered my children.) } \\
\text { "Kinabahan" (got nervous) } \\
\text { "Baka hindi ko kayanin kasi may pre-existing condition ako." (I might not be able to do it because I have pre-existing conditions.) } \\
\text { "Fear because we will be assuming roles we were not used to." }\end{array}$ \\
\hline No surprise & $\begin{array}{l}\text { KIls } \\
\text { "We were called to action. It was a go." }\end{array}$ \\
& $\begin{array}{l}\text { FGDs } \\
\text { "I was not really surprised because as a national university hospital, we are really big." } \\
\text { "I guess we did not have a choice." } \\
\text { "The call to service was louder than other aspects. We had to sacrifice training. We just have to live with it." } \\
\text { "We view everything as part of our duty." }\end{array}$ \\
\hline Anxiety & $\begin{array}{l}\text { FGDs } \\
\text { "Ano ang mangyayari sa patients natin sa PGH? Saan sila pupunta kung puro COVID tayo?" (We were worried for our patients if we } \\
\text { become a COVID referral center.) } \\
\text { "Paano na ang aming training?" (How will be our training?) }\end{array}$
\end{tabular}


Appendix Table 3. Responses by the key informants and the FGD participants on the preparations and plans on being a COVID referral center

On the Overall Operations

\section{On terms with DOH:}

"May apat na kailangan magka-sundo tayo Una, COVID positive only. Pangalawa, full support ng DOH. Pangatlo, may manpower augmentation. Pang-apat, dapat may command center tayo." (We need to agree on 4 things.)

"We went into the abnormal mode right away."

"The COVID operations will have surgeons. Dalawa lang ang magiging team. Isang logistics para sa mga hindi gumagalaw at isang manpower para sa mga gumagalaw." (There will be 2 teams - logistics for all that don't move and manpower for all that move.)

"Ang concept ng Crisis Committee kaya puro surgeons yan para hindi na magtrabaho ang mga internists. That's the idea, sabi namin sa HICU, IDS, at Pulmo - lahat na kailangan nyo to make this work, tell us - you will take care of the science and the clinical part, we will take care of the logistics." (Surgeons will work on the needs/logistics, internists will work on the science, the clinical part.)

"Gumawa kami ng malaking dashboard na real-time electronic. So pagtingin mo sa dashboard makikita mo kung ilan yung bakante. Endorsements were also through the dashboard." (We made a big dashboard, one look, and you can see the vacancies.")

"Mas maganda, may infographics to communicate with the whole staff. That's why that committee saved us a lot of trouble." (It was better we had infographics.)

"How can I help HICU send their message?"

"We enhanced the existing electronic medical records, RADISH, so that the charts are all electronic."

"Critical also in the operations was the early release of COVID results by the laboratory so the patients can be directed to the appropriate ward immediately."

"Having our own swabbing booth where many workers can be swabbers helped."

"We also developed a "tele-kamustahan" visitor access program."

"We also had connections with Loyola (funeral service), MMDA, and the city of Manila for handling of corpse."

"We built PGH to be well-equipped, well-funded, and well-manned."

On surge capacity:

"Ide-describe ko sa inyo ang COVID operations na sa rubber band. I-stretch ko sya up to this (hand gesture, stretching). Pero kaya ko rin siya i-shrink up to this, at kaya ko din siya i-restretch ko din siya up to this." (Like a rubber band, I can stretch it to this, shrink to this, re-stretch again.)

"We connected with the City of Manila kasi dyan naman nanggaling yung mga PUI. So we connected with them and helped set up the quarantine center in Del Pan so only the severe cases go to us."
"There might have been misses in communication at the start but we went along and the set-up became clear."

"Even up to now, policies and guidelines change. Now we understand better. HICU now communicates better especially with the publicity materials. Those really help."

"It was like developing best practices on the go."

"For the COVID referrals, the Command Center really helped because it centralized the transfers."

"Maganda naging response ng IEC Team. Nakita namin yung mga infographics sa mga facebook, viber, and other chat groups trickled down by the heads to the different departments and units." (The IEC had a good response with infographics trickled down by heads to their respective units/departments) 
The Development of the PGH as a Referral Center in the COVID-19 Pandemic

Appendix Table 3. Responses by the key informants and the FGD participants on the preparations and plans on being a COVID referral center (continued)

"Why don't we create a negative pressure?"

"You can't create a negative pressure in the existing building. If you want to create a negative pressure it should be built together with the building. Otherwise, it will be costly."

"Let us just provide airflow, an enhanced airflow - a unidirectional flow of air."

"6 air exchanges per hour"

"The construction is actually simply to put air movement in the ward."

\section{On staffing}

"The idea of staffing estimate considered contact exposure - if 100 kayo marami. Kung gawin ko lang na 30 dahil konti na pasyente. So, ginawa ang 3 teams - Team 1,2,3. Ang mangyayari magduduty ka ng one week. Mag-off ka ng 2 weeks. As advised by IDS, the contact exposure should be less." (If 100, there are many but if I will make it 30 since there are less patients, thus 3 teams were made, one week duty and 2 weeks off.)

"Parang counterintuitive, dami mong kailangan gawin pero hinati mo to three ang iyong staff because you want them out of the hospital for less exposure because hindi mo pa nga alam kung anung mangyayari." (It looks counterintuitive, you have to do a lot but you divided your staff into 3, because you want them out of the hospital for less exposure because you do not know yet what will happen.)

On support to the PGH staff
"Ang ginawa ng COVID operation is nothing but to protect the health
care workers. Tingin ko yun ang number one na naprovide ng COVID
operations." (The COVID Operation provided protection to the health
care workers.)

"Tingin ko lahat ng health care workers ngayon they feel comfortable kasi alam nila na they are protected." (I think the health care workers now feel comfortable because they know they are protected.)

\section{With regard training and safety}

"Isang pinakamalaking impact na nagpataas ng morale ng lahat ng health care worker ay ang Safety Officer. It gives them confidence kasi alam nila protected sila kasi lahat ng movement nila, may nanonood when they don and doff." (One of the things which had a big impact on the health care worker is the safety officer. It gives them confidence when they know somebody watches them don and doff.)

"Ang nurse, papasok ka ng 6 AM, ang doctor 7 AM, ang institutional worker 8 AM para hindi sabay sabay sa donning and doffing staggered sila." (The nurse will come in at 6 AM, the doctor at 7 AM, the institutional worker $8 \mathrm{am}$, staggered donning and doffing.)

"Our KN95 and N95 masks had to be fit-tested. Respirator masks were provided as necessary."

"Since intubation was unique, we were the first group (referring to anesthesiologists) to simulate with video laryngoscopes and aerosol boxes. We developed our protocols. We then had simulation with all the people involved."
"I trusted the system that the structure they made was protective."

"The zoning was initially problematic. We were a COVID center but within the same building, we had non-COVID areas. Ideally, there has to be a separate structure for just COVID."

\begin{abstract}
"Sinabihan na kami ng aming chief, prepare na hatiin tayo sa 3 teams." (Our chief told us to prepare as we will be divided into 3 teams.)
\end{abstract}

"Ma-pull out na tayo kasi i-consolidate na ang ating manpower and idivide tayo into 3 teams." (We will be pulled out and our manpower consolidated to be divided into 3 teams.)

"We are thankful to the other departments for joining us in going on duty in the COVID areas."

"Kulang talaga sa tao, mahirap and immediate pullout para sa mga areas na mag-open." (The manpower is lacking. It was difficult to pull out people right away to man areas that will open.)
"Our department and PGH were very supportive. The message is priority is our safety."

"Basta yung moral support andun. Kasama na ang mga accommodation, transportation. Masaya na kami sa mga ganon kasi ang sa hirap ngayon." (For as long as the moral support is there plus accommodation and transportation, we are happy with that because times are difficult.)

"Pero maganda naman po sa PGH, binigyan po kami ng proper training as safety officer. Na-appreciate namin yung value ng pagiging safety officer." (The good thing is we were given proper training on how to be a safety officer. We appreciated value of being a safety officer.)

"Nag-aral muna kami paano tamang pagsuot ng PPE." (We learned first how to wear PPEs properly.)

"COVID 19 pathways were very helpful for the non-IM trainees. In that way, we were not totally lost." 
Appendix Table 3. Responses by the key informants and the FGD participants on the preparations and plans on being a COVID referral center (continued)

On transportation and housing:

"Dahil nag lockdown, walang transport para sa empleyado. How do we solve this? Paano makakarating mga empleyado dito? The solution, naghire kami ng Beep Service." (Because of the lockdown, the employees did not have transport. How can they report to the hospital? The solution, we hired a Beep Service.)

"We needed to address housing too. Maghahanap tayong ng iba pang paraan para ma-house yung mga tao to also reduce the transportation expense." (We need to look for ways to provide housing for them.)

"The meals, the housing, that meant about 1,800 people at any one time."
"Worried din ang mga tao kung paano sila makakapasok. Very helpful yung transportation support." (The people were worried how they will report for work. The transportation and housing support were very helpful.)

"There is PGH Care Group for psychological needs."

\section{With regard checking of health status:}

"Andyan po agad yung UPHS, nag-monitor sa akin." (The UPHS was there right away to monitor me.)

"Sobrang satisfied po sa Health Service kasi po action po talaga sila. Sa pagtawag kapag po nailagay yung name mo sa exposed or close contact or certain na infected, talagang tatawagan ka nila." (Am so satisfied with the Health Service because they are quick to action. Once your name is in the exposed, close contact or certainly infected, they will call you.)

"Sobrang satisfied po sa ano pagiging active ng UP Health Service and everyday po din talaga silang nagchecheck ng mga kung may symptoms ka." (Am so satisfied with the UP Health Service being active, every day they check on you for symptoms.

\section{On funds}

"The Bayanihan Act was declared by the President with special mention of PGH because it's a COVID referral hospital with additional budget. We had the support."

"We needed to re-program our savings too."

"Kung hindi tayo nag-volunteer makakakuha kaya tayo ng donation na ganyan?" (If we did not volunteer, could we have gotten all those donations?)

"We have commitment from government. We have commitment from the University. We have commitment from the private organizations."

"The President of the University ordered that the Bayanihan Center be the organized call center and be the centralized repository of donations. That really helped a lot also."

"We built a war chest, a very big cash war chest."

\section{On supplies}

"We saved on PPEs because of the friendly ward set up. Kung ward kasi open, isang PPE lang gagamitin mo for the duty." (Since it is a ward, you just use one PPE for the duty.)

"The supplies of PPE were allocated well. Though at some point, the levels of PPEs were confusing." 
Appendix Table 3. Responses by the key informants and the FGD participants on the preparations and plans on being a COVID referral center (continued)

"Ang pwede gawin ng ibang hospitals na non-COVID, puede natin ipasa sa kanila." (The non-COVID cases can be taken in by nonCOVID hospitals.)

"Let us bring the non-COVID to the community - so we're looking at satellite clinics. There will be PGH primary Satellite clinics linking to our OPD."
"In our specialty dealing with cancer patients, we had to look for guidelines being used in other countries for prioritization of our cases."

"We had to use a different platform to follow up on our patients."

"The network referral system was poor. We did not know where to send our non-COVID patients."

\section{On returning the non-COVID services}

"We're trying to shrink the operation, the command area, so that we can free up the whole hospital for the non-COVID services."

"We create a transition team outside of the COVID Operations."

"The plan is to de-escalate because you want to have that steady state of COVID and non-COVID."

Appendix Table 4. Responses from FGD participants on lessons learned and what improvements can be made

Communication really has to be two-way - that's one major factor that could have led to improvement. What could have been improved is getting more feedback from the grassroots as it went along."

"Communication is really important - between people, between departments. Maraming pwedeng maging improvement if they just talk."

[There can be lots of improvement if they just talk.]

"Sana may recognition like for those with no absences at iba pa." [I hope there will be some form of recognition for those who never absented and others.]

"Ang gusto naming reward ay pahinga. Monetizing ay ok din." [Getting rest is a reward we want, but we welcome monetizing the reward too.]

Appendix Table 5. Responses by the key informants and FGD participants on how the experience as a whole helped PGH "Yung mga bagay na hindi naming in-expect na magagawa naming, kinaya naman namin." [This has taught as many things: being sensitive to public health measures like personal hygiene, handwashing, PPEs, engineering controls, staffing."]

"This has taught us that we need forward thinking and anticipation of what can possibly happen."

"Naging catalyst ang COVID for us to procure importanteng equipment to transition to digital. It benefited us during COVID and definitely it will benefit the hospital for the years to come." (COVID became a catalyst for the procurement of important equipment so that it can transition to digital.)

"Naging maganda kasi yung access ng lahat sa RADISH. We can access the charts from the office. Electronic and online na ang charting." (We got good access with RADISH. Charting has become online and electronic.)

"Pagiging adaptable ng PGH sa technology. Both beneficial sa patients at employees." (PGH became adaptable to technology which became beneficial to patients and employees.)

"Nadagdagan pa yung kaya nating ibigay na services." (We have added to what services we can offer.)

"Merong ganung spirit sa mga taga-PGH, yung sosolusyunan po hanggang makakaya." [In PGH, we have that spirit for as long as we can, we will try to give solutions.] 